\title{
Cutaneous Metastasis of Bladder Cancer
}

\author{
Mounia Bennani*, Selma Benkirane, Sara Elloudi, Zakia Douhi, Hanane Baybay and Fatima \\ Zahra Mernissi \\ Department of dermatology, Hassan II hospital University of Fès, Morocco \\ *Corresponding author: Mounia Bennani, Department of dermatology , Hassan II hospital Univesity of Fès, Morocco
}

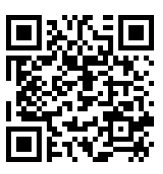

\begin{tabular}{|c|c|}
\hline ARTICLE INFO & ABSTRACT \\
\hline Received: 慧 March 12, 2020 & \multirow{2}{*}{$\begin{array}{l}\text { Citation: Mounia B, Selma B, Sara E, Zakia D, Hanane B, et al . Cutaneous Metastasis of } \\
\text { Bladder Cancer. Biomed J Sci \& Tech Res 27(2)-2020. BJSTR. MS.ID.004466. }\end{array}$} \\
\hline Published: 慧 April 23, 2020 & \\
\hline
\end{tabular}

\section{Introduction}

Skin metastases (SM) are infrequent secondary locations of deep neoplasia that can sometimes be indicative of primary cancer. They represent 0.2 to $10 \%$ of metastases from solid tumors[1]. The most frequent primary tumors in men were carcinoma of the lung (24\%), carcinoma of the large intestine (19\%), melanoma (13\%), and squamous cell carcinoma of the oral cavity (12\%). The most common primary tumors in women were carcinoma of the breast

(69\%), carcinoma of the large intestine (9\%), melanoma (5\%), and carcinoma of the ovary (4\%)[2].The incidence of cutaneous involvement by all urological malignancies is $1.1 \%$ to $2.5 \%$ [3]. The kidney is the most common organ to serve as a source of metastasis to the skin[4]. Bladder cancers are less likely to metastasize to the skin. We report a new case of skin metastases presenting as a large tumor in the thoracic level in a patient followed for a urothelial carcinoma of the bladder.

\section{Case Report}

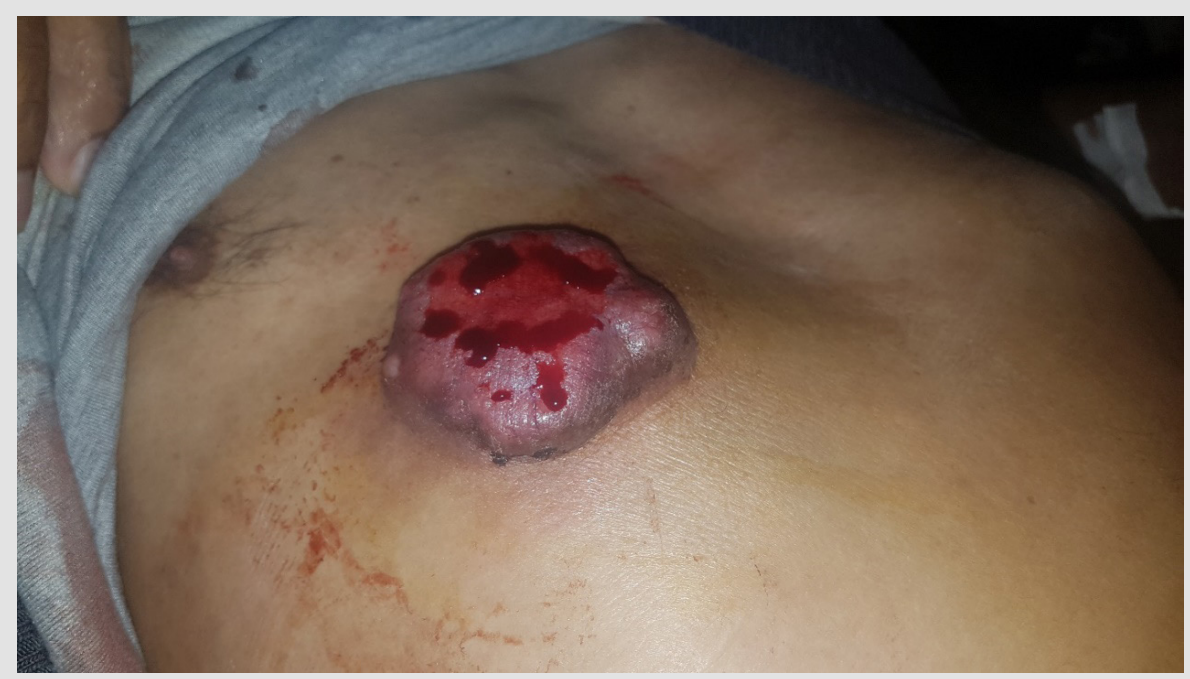

Figure 1: Pigmented tumor of $5 / 6 \mathrm{~cm}$ of large, an ulcerated and bleeding surface in anterior surface of the thorax.

We report the case of a 66-year-old patient, followed for a high-grade urothelial carcinoma for 2 years, initially mesa static at the level of the prostate. The patient was then put on neoadjuvant chemotherapy, but he was lost to follow-up and presented himself after 5 months, with extension of the tumor to the gallbladder, and the urethral masses, the internal obturator muscle and bilateral external iliac lymphadenopathy, as well as adrenal metastasis, with an examination of oncologists the presence of a skin tumor in the 
right thoracic level, hence a dermatological opinion was requested. A dermatological examination on an objectified presence of a pigmented tumor of $5 / 6 \mathrm{~cm}$ of large, an ulcerated and bleeding surface, sitting at the level of the anterior surface of the thorax, on the right side (Figure 1). At the dermoscopy we had pigmented areas without structures, with the presence of a polymorphic vascularization made of arborising vessels as well as tortuous vessels (Figure 2), in front of this aspect associated with the clinical context we first thought to a skin metastasis bladder tumor, and a skin biopsy was performed confirming this diagnosis. The patient was then kept on palliative chemotherapy based on cisplatin + gemcitabine and died 2 months later.

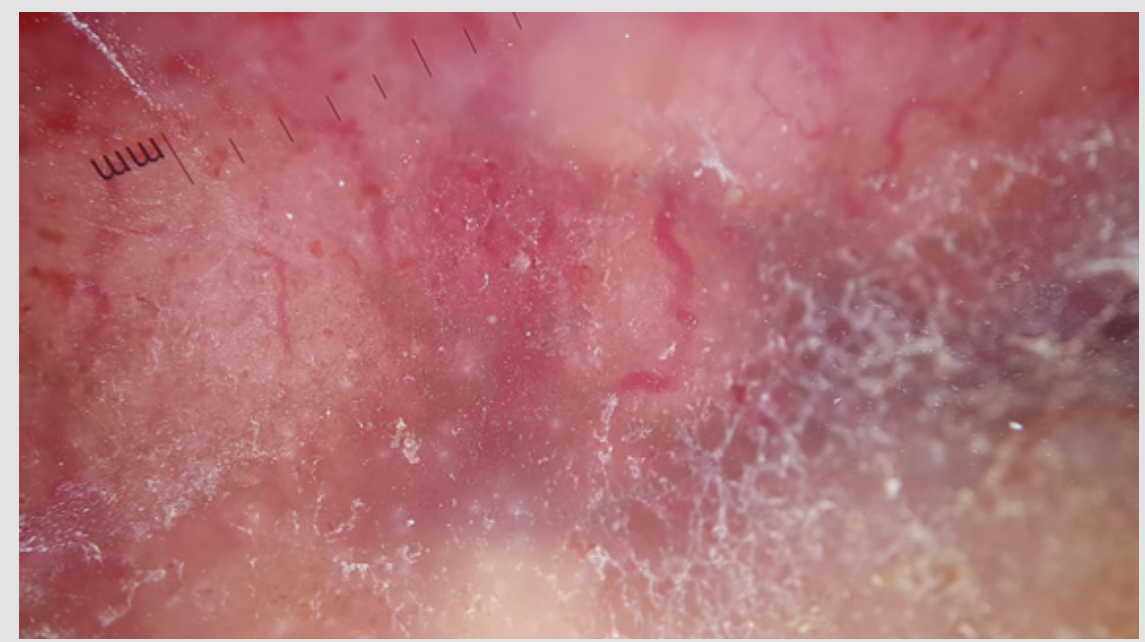

Figure 2: Dermoscopic image showing tortuous vessels (arrow) and arborizing vessels (circle).

\section{Discussion}

Only $5.3 \%$ of all malignancies lead to cutaneous metastasis. Out of these, $1.34 \%$ are linked to underlying genitourinary malignancy; bladder cancer accounts for $0.84 \%$ of these [5] with a limited number of published cases, It usually metastasizes to regional lymph nodes, liver, lungs and bones [1] Large 20-year retrospective Taiwanese study found only 2 cases of skin metastases among 911 patients with bladder and ureter cancer [6] and Kishi, et al. [7] reported that $66.7 \%$ of patients with $\mathrm{T} 3$ and $\mathrm{T} 4$ tumors had metastatic disease. Cutaneous involvement from bladder cancer is achieved by direct tumor invasion, hematogenous routes, lymphatic spread, and direct seeding due to iatrogenic implantation [8].Iatrogenic implantation is the most common cause of seeding outside of the urinary tract [9] and its due to surgical treatment of these tumors, including cystectomy, partial cystectomy, TURBT, and other procedures [8]. The clinical appearance of these lesions varies and may mimic other dermatologic diseases. The lesions can be solitary or multiple, and can have a nodular, fibrotic, and inflammatory appearance[8].

In urological cancer with cutaneous metastasis,several aspects have been described in the literature,like, A cutaneous erysipelas-like lesion [10] Zosteriform cutaneous metastases [11] or Herpetiform cutaneous metastases [12], but the most common clinical picture is an infiltrated plaque or nodule [10] Ulcerated swelling, subcutaneous nodules, violaceous papules, and ulcerated plaques have been reported [1] in our patient the appearance was that of a large tumor with ulcerated surface. Dermoscopy of skin metastases has been recently reported in the literature [13], the most reported sign was a polymorphic vascularization made of arborising vessels, as well as serpiginous, but these aspects were not retained as specific, since they can be found even in front of a primary skin tumor, such as melanoma or squamous cell carcinoma. Local excision, radiotherapy, chemotherapy, immunological and combination therapy have been reported in previous studies [14]. Due to the poor outcomes of these patients, the treatment options are limited and primarily supportive in nature. The prognosis of any cancer with cutaneous metastasis is poor; with regard to bladder cancer with cutaneous metastasis, median survival time is $<12$ months [10].

\section{Conclusion}

We report a new case of skin metastasis of a bladder tumor, in the form of a pigmented tumor in a patient with multiple visceral metastases. Although cutaneous metastasis is a rare dermatological condition, cutaneous metastasis should be included in the differential diagnosis of tumoal lesion. Skin biopsy should be performed to prevent misdiagnosis. For the patients with urologic malignancies, we suggest that all urologists should increase attention to the physical examination of the skin because skin lesions can be the first sign of silent or recurrent urologic malignancies.

\section{References}

1. Nashan D, Müller ML, BraunFalco M, Reichenberger S, Szeimies RM, et al. (2009) Cutaneous metastases of visceral tumours: A review. J Cancer Res Clin Oncol 135(1): 1-14. 
2. Brownstein MH (1972) Patterns of cutaneous metastasis. Archives of Dermatology105(6): 862-868.

3. Block CA, Dahmoush L, Konety BR (2006) Cutaneous metastases from transitional cell carcinoma of the bladder. Urology 67: 846.e15-17.

4. Mueller TJ, Wu H, Greenberg RE, Hudes G, Topham N, et al. (2004) Cutaneous metastases from genitourinary malignancies. Urology 63(6): 1021-1026.

5. Weizer AZ, Shariat SF, Haddad JL, Escudier S, Lerner SP (2002) Metastatic transitional cell carcinoma of the urinary bladder to the shoulder girdle. Rev Urol 4: 97-99.

6. Hu SC, Chen GS, Wu CS (2009) Rates of cutaneous metastases from different internal malignancies: experience from a Taiwanese medical center. J Am Acad Dermatol 60(3): 379-387.

7. Saito S (1998) Solitary Cutaneous Metastasis of Superficial Bladder Cancer. Urologia Internationalis 61(2): 126-127.

8. Narayana MA, Patnayak R, Rukmangadha N, Chowhan AK, Kottu R, et al. (2014) Cutaneous metastasis of transitional cell carcinoma of the urinary bladder: Cytological aspect. J Cytol 31: 50-52.

ISSN: 2574-1241

DOI: $10.26717 /$ BJSTR.2020.27.004466

Mounia Bennani. Biomed J Sci \& Tech Res

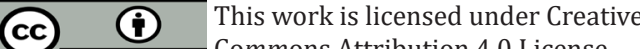

Submission Link: https://biomedres.us/submit-manuscript.php
9. Tal Cohen, Daniel Ricchiuti, Mark Memo (2017) Bladder cancer that metastasized to the skin: A unique presentation that signifies poor prognosis. Rev Urol 19(1): 67-71.

10. Chang CP, Lee Y, Shih HJ (2013) Unusual presentation of cutaneous metastasis from bladder urothelial carcinoma. Chin J Cancer Res 25(3): 362-365.

11. Thomaidou E, Armoni G, Klapholz L, Hadayer N, Maly A, et al. (2018) Zosteriform cutaneous metastases. Clinical and Experimental Dermatology 43(6): 734-736.

12. Somani BK, Prita D, Grant S, Nabi G, N’Dow J (2006) Herpetiform cutaneous metastases from transitional cell carcinoma of the urinary bladder: Immunohistochemical analysis. Journal of Clinical Pathology. BMJ 59(12): 1331-1333.

13. Deinlein T, Haenssle HA, Fink C, HofmannWellenhof R, Blum A (2018) Dermatoskopie von kutanenMetastasen 70(2): 142-144.

14. Nashan D, Meiss F, BraunFalco M, Reichenberger S (2010) Cutaneous metastases from internal malignancies. Dermatol Ther 23(6): 567-580.

$\begin{array}{ll}\text { BIOMEDICAL } & \text { Assets of Publishing with us } \\ \text { RESEARCHES } & \text { - Global archiving of articles } \\ \text { - Immediate, unrestricted online access } & \text { - Rigorous Peer Review Process } \\ & \text { - Authors Retain Copyrights } \\ & \end{array}$

